PENINGKATAN KOMPETENSI GURU BINAAN DALAM MENYUSUN RPPH MELALUI WORKSHOP DI GUGUS PAUD RANTEPAO KABUPATEN TORAJA UTARA

\section{Nurjanna $\mathbf{M}$.}

Dinas Pendidikan Kabupaten Toraja Utara

Email: nurjannah.marading@yahoo.com

http://ojs.unm.ac.id/index.php/Insani/index

Abstrak. Penelitian ini merupakan penelitian kualitatif deskriptif yang menggunakan rancangan Penelitian Tindakan Sekolah (PTS). Penelitian ini bertujuan untuk meningkatkan kompetensi guru binaan dalam menyusun Rencana Pelaksanaan Pembelajaran Harian (RPPH) melalui workshop di gugus PAUD Rantepao, Kecamatan Rantepao, Kabupaten Toraja Utara. Pelaksanaan penelitian dilaksanakan dalam bentuk siklus yang berulang, di dalamnya terdapat empat tahapan kegiatan yaitu perencanaan, pelaksanaan, observasi, dan refleksi. Hasil penelitian menunjukkan perhitungan akhir rata-rata mengenai kompetensi guru dalam menyusun RPPH, setelah diberi tindakan ternyata optimalisai kompetensi tersebut baru mencapai $71 \%$ tergolong "baik", hal ini disebabkan karena ada beberapa komponen yang belum maksimal dicapai oleh guru antara kemampuan memahami komponenkomponen RPPH termasuk kompetensi dasar yang harus dituangkan pada penyusunan RPPH.

Kata Kunci: Kompetensi Guru, RPPH, Workshop Gugus PAUD

\section{INDONESIAN JOURNAL OF EDUCATIONAL STUDIES (IJES)}

\section{E-ISSN: 2621-6744 P-ISSN: 2621-6736}

Submitted: March, $4^{\text {th }} 2019$ Accepted : April, $27^{\text {th }} 2019$

Abstract. This research is a descriptive qualitative study using the School Action Research design. This study aims to improve the competency of assisted teachers in preparing the Daily Learning Implementation Plan through workshops in the PAUD Rantepao cluster, Rantepao District, North Toraja Regency. The implementation of the research is carried out in the form of a repetitive cycle, in which there are four stages of activity, namely planning, implementation, observation, and reflection. The results showed that the average final calculation of teacher competency in preparing $\mathrm{RPPH}$, after being given the action it turned out that the competency optimization had only reached $71 \%$ classified as "good", this was because there were several components that were not maximally achieved by the teacher between the ability to understand the components RPPH includes basic competencies that must be set forth in the preparation of RPPH. 


\section{PENDAHULUAN}

Pendidikan merupakan investasi dalam pengembangan sumber daya manusia dan dipandang sebagai kebutuhan dasar bagi masyarakat yang ingin maju. Komponen-komponen sistem pendidikan yang mencakup sumber daya manusia dapat digolongkan menjadi dua yaitu: tenaga kependidikan guru dan nonguru. Menurut Undang-Undang Nomor 2 tahun 1989 tentang Sistem Pendidikan Nasional menyatakan, "komponen-komponen sistem pendidikan yang bersifat sumber daya manusia dapat digolongkan menjadi tenaga pendidik dan pengelola satuan pendidikan (penilik, pengawas, peneliti dan pengembang pendidikan). Usaha-usaha untuk mempersiapkan guru menjadi profesional telah banyak dilakukan.

Kenyataan menunjukkan bahwa tidak semua guru memiliki kinerja yang baik dalam melaksanakan tugasnya. Berdasarkan kenyataan begitu berat dan kompleksnya tugas serta peran guru tersebut, perlu diadakan supervisi atau pembinaan terhadap guru secara terus menerus untuk meningkatkan kompetensinya. Kompetensi guru perlu ditingkatkan agar usaha membimbing siswa untuk belajar dapat berkembang.

Direktorat Pembinaan menyatakan "kualitas pendidikan sangat ditentukan oleh kemampuan sekolah dalam mengelola proses pembelajaran, dan lebih khusus lagi adalah proses pembelajaran yang terjadi di kelas, mempunyai andil dalam menentukan kualitas pendidikan konsekuensinya, adalah guru harus mempersiapkan (merencanakan ) segala sesuatu agar proses pembelajaran di kelas berjalan dengan efektif". Hal ini berarti bahwa guru sebagai fasilitator yang mengelola proses pembelajaran di kelas mempunyai andil dalam menentukan kualitas pendidikan. Konsekuensinya adalah guru harus mempersiapkan (merencanakan) segala sesuatu agar proses pembelajaran di kelas berjalan dengan efektif.

Perencanaan pembelajaran merupakan langkah yang sangat penting sebelum pelaksanaan pembelajaran. Perencanaan yang matang diperlukan supaya pelaksanaan pembelajaran berjalan secara efektif. Perencanaan pembelajaran dituangkan ke dalam Rencana Pelaksanaan Pembelajaran Harian (RPPH) atau beberapa istilah lain seperti desain pembelajaran, skenario pembelajaran. RPPH memuat KD, indikator yang akan dicapai, materi yang akan dipelajari, metode pembelajaran, langkah pembelajaran, media pembelajaran, dan sumber belajar serta penilaian.

RPPH dikembangkan oleh guru pada satuan pendidikan . Guru pada satuan pendidikan berkewajiban menyusun RPPH secara lengkap dan sistematis. Masalah yang terjadi di lapangan masih ditemukan adanya guru baik yang PNS maupun yang Non PNS tidak bisa memperlihatkan RPPH yang dibuat dan bagi guru yang sudah membuat RPPH masih ditemukan adanya guru yang belum melengkapi komponen penilaian, serta langkah-langkah kegiatan pembelajarannya belum menerapkan kegiatan saintific pada kegiatan inti. Penilaian hasil belajar merupakan satu kesatuan yang tidak dapat dipisahkan.

Dengan keadaan demikian, peneliti sebagai pembina sekolah berusaha untuk memberi bimbingan pada guru dalam menyusun RPPH secara lengkap sesuai dengan tuntutan pada standar proses dan standar penilaian yang merupakan bagian 
dari standar nasional pendidikan. Rencana Pelaksanaan Pembelajaran Harian harus dibuat agar kegiatan pembelajaran berjalan sistematis dan mencapai tujuan pembelajaran. Tanpa Rencana Pelaksanaan Pembelajaran Harian, biasanya pembelajaran menjadi tidak terarah. Oleh karena itu, guru harus mampu menyusun RPPH dengan lengkap berdasarkan silabus yang disusunnya. Rencana Pelaksanaan Pembelajaran Harian sangat penting bagi seorang guru karena merupakan acuan dalam melaksanakan proses pembelajaran.

\section{METODE PENELITIAN}

Penelitian dilaksanakan dengan menggunakan metode penelitian tindakan. Jenis tindakan yang dilakukan adalah workshop untuk memberikan teori dan praktik langsung yang diterapkan untuk meningkatkan kompetensi guru dalam menyusun RPPH. Perencanaan dalam penelitian ini berupa penyusunan rancangan tindakan yang dituangkan dalam program workshop bagi guru. Pelaksanaan tindakan adalah implementasi tindakan dalam kegiatan pembinaan guru. Pelaksanaan penelitian dilaksanakan dalam bentuk siklus yang berulang, di dalamnya terdapat beberapa tahapan kegiaatan dalam tiga siklus, masing-masing siklus terdiri atas empat langkah yaitu perencanaan, pelaksanaan, observasi, dan refleksi. Penelitian Tindakan Sekolah ini, dilakukan di wilayah Binaan Kecamatan Rantepao, yaitu fokus di gugus Rantepao Kecamatan Rantepao Kabupaten Toraja Utara dengan jumlah guru sebanyak 51 orang yang terdiri dari guru kelas dan Kepala Sekolah.

Instrumen dalam penelitian ini berupa angket tentang perangkat RPPH yang disebar melalui kepala Taman Kanak-Kanak ketika melaksanakan kunjungan sekolah. Proses analisis data penelitian ini dimulai sejak sebelum peneliti memasuki lapangan. Peneliti/pengawas sebelum workshop di gugus melakukan kunjungan sekolah dalam rangka membagikan angket dan melaksanakan observasi sejauh mana keberhasilan guru-guru dalam menyusun RPPH. Analisis data dilanjutkan ketika peneliti berada di lapangan sampai peneliti menyelesaikan kegiatan di lapangan. Data-data yang telah terkumpul digunakan sebagai acuan untuk mengetahui keterlaksanaan proses pembinaan serta hasil pembinaan yang dicapai. Data tersebut dianalisis dan diolah menggunakan teknik analisis deskriptif sebagai acuan dalam menarik kesimpulan.

\section{HASIL DAN PEMBAHASAN}

Penelitian tindakan sekolah/kepengawasan (PTS/Kp) ini dilaksanakan dengan melalui workshop terhadap guru sebagai mitra kerja di sekolah. Observasi dan refleksi selama penelitian berlangsung di kegiatan gugus PAUD Kecamatan Rantepao yang di dalamnya terdapat seluruh guru binaan. Sebelum melaksanakan workshop di gugus, mereka mengisi angket yang telah diberikan peneliti/pengawas pada waktu melakukan kunjungan sekolah untuk mendapat masukan atau informasi dari data-data guru binaan. Hasil penelitian ini berupa data Pra Pembimbingan Kompetensi Guru Terhadap Penyusunan RPPH (Evaluasi Diri) dan Pasca Pembimbingan Kompetensi Guru Terhadap Penyusunan RPPH (Evaluasi Diri) di gugus Rantepao Kecamatan Kabupaten Toraja Utara. 
Tabel 1

Pra Pembimbingan Kompetensi Guru Terhadap Penyusunan RPPH (Evaluasi Diri)

\begin{tabular}{|c|c|c|c|}
\hline No. & Instrumen & Jawaban responden & Prosentase \\
\hline \multirow[t]{3}{*}{1.} & \multirow{3}{*}{$\begin{array}{l}\text { Memahami Penyusunan RPPH } \\
\text { berdasarkan kurikulum } 2013 \\
\text { PAUD }\end{array}$} & a. Sangat memahami & $39 \%$ \\
\hline & & b. Memahami sebagian & $40 \%$ \\
\hline & & c. Belum tahu & $21 \%$ \\
\hline \multirow[t]{3}{*}{2.} & \multirow[t]{3}{*}{ Memahami Kompetensi dasar } & a. Memahami & $56 \%$ \\
\hline & & $\begin{array}{l}\text { b. Memahami } \\
\text { sebahagian }\end{array}$ & $34 \%$ \\
\hline & & c. Belum tahu & $10 \%$ \\
\hline \multirow[t]{3}{*}{3.} & \multirow{3}{*}{$\begin{array}{l}\text { Mengetahui pentingnya } \\
\text { penyusunan RPPH }\end{array}$} & a. Tahu & $56 \%$ \\
\hline & & b. Tahu sebagian & $23 \%$ \\
\hline & & c. Belum tahu & $21 \%$ \\
\hline \multirow[t]{3}{*}{4.} & \multirow{3}{*}{$\begin{array}{l}\text { Mengetahui prinsip-prinsip } \\
\text { penyusunan RPPH }\end{array}$} & a. Tahu & $41 \%$ \\
\hline & & b. Tahu sebagian & $57 \%$ \\
\hline & & c. Belum tahu & $2 \%$ \\
\hline \multirow[t]{3}{*}{5} & \multirow{3}{*}{$\begin{array}{l}\text { Memahami } \\
\text { komponen RPPH }\end{array}$} & a. Sangat memahami & $56 \%$ \\
\hline & & b.Memahami sebagian & $42 \%$ \\
\hline & & c.Belum Tahu & $2 \%$ \\
\hline \multirow[t]{2}{*}{6} & \multirow[t]{2}{*}{ Hasil penyusunan RPPH } & $\begin{array}{l}\text { a.Yang menyusun benar } \\
25 \text { orang }\end{array}$ & $49 \%$ \\
\hline & & $\begin{array}{l}\text { b. Yang menyusun salah } \\
26 \text { orang }\end{array}$ & $51 \%$ \\
\hline
\end{tabular}

Melihat data di atas, dapat disimpulkan bahwa guru yang tahu dan paham tentang penyusunan RPPH hanya 39\% dengan kategori kurang, memahami kompetensi dasar hanya 56\% dengan kategori "cukup" memahami pentingnya RPPH terdapat 56\% atau kategori "cukup" Memahami prinsip-prinsip penyusunan RPPH terdapat $41 \%$ atau kategori "kurang" memahami komponen-komponen RPPH terdapat $56 \%$ atau kategori "cukup" sedangkan dalam penyusunan RPPH terdapat 49\% dengan kategori "kurang".

Berdasarkan analisa peneliti bahwa penyebab masih rendahnya hasil instrument yang disebar kepada guru sebelum pelaksanaan workshop yaitu selain memang sebahagian belum memahami, penyebab lain adalah mereka masih ragu-ragu dalam mengisi instrument mereka beranggapan jangan sampai kita dikategorikan sudah paham semuanya dan tidak mendapat lagi materi workshop yang memadai. Hal ini diungkapkan oleh beberapa responden pada waktu workshop. 
Pembahasan terhadap permasalahan penelitian maupun hipotesis tindakan berdasarkan analisis data kualitatif, hasil penelitian dan profil kelompok guru binaan di gugus Rantepao Kecamatan Kabupaten Toraja Utara. Berikut adalah profil guru sesudah mengikuti pembinaan tentang penyusunan RPPH melalui workshop.

Tabel 2

Pasca Pembinaan Kompetensi Guru Terhadap Penyusunan RPPH Berdasarkan Siklus

\begin{tabular}{|c|c|c|c|c|c|c|}
\hline No. & Instrumen & $\begin{array}{l}\text { Jawaban } \\
\text { Responden }\end{array}$ & Siklus I & Siklus II & Siklus III & $\begin{array}{l}\text { Rata- } \\
\text { rata }\end{array}$ \\
\hline \multirow[t]{3}{*}{1.} & \multirow{2}{*}{$\begin{array}{l}\text { Memahami } \\
\text { Penyusunan RPPH } \\
\text { berdasarkan }\end{array}$} & $\begin{array}{l}\text { a. Sangat } \\
\text { memahami }\end{array}$ & $50 \%$ & $65 \%$ & $75 \%$ & $63 \%$ \\
\hline & & $\begin{array}{l}\text { b. Memahami } \\
\text { sebagian }\end{array}$ & $50 \%$ & $35 \%$ & $25 \%$ & $37 \%$ \\
\hline & PAUD & $\begin{array}{l}\text { c. Belum } \\
\text { memahami }\end{array}$ & 0 & 0 & 0 & 0 \\
\hline
\end{tabular}

\begin{tabular}{|c|c|c|c|c|c|c|}
\hline \multirow[t]{4}{*}{2.} & \multirow{4}{*}{$\begin{array}{l}\text { Memahami } \\
\text { kompetensi dasar }\end{array}$} & a.Tahu & \multirow{2}{*}{$\begin{array}{l}60 \% \\
40 \%\end{array}$} & \multirow{2}{*}{$\begin{array}{l}65 \% \\
35 \%\end{array}$} & \multirow{2}{*}{$\begin{array}{l}70 \% \\
30 \%\end{array}$} & \multirow{2}{*}{$\begin{array}{l}65 \% \\
34 \%\end{array}$} \\
\hline & & $\begin{array}{l}\text { b. Memahami } \\
\text { sebahagian }\end{array}$ & & & & \\
\hline & & a. Belum tahu & $4 \%$ & - & - & $1 \%$ \\
\hline & & & - & - & - & - \\
\hline \multirow[t]{4}{*}{3.} & \multirow{4}{*}{$\begin{array}{l}\text { Mengetahui } \\
\text { pentingnya } \\
\text { penyusunan RPPH }\end{array}$} & a. Tahu & $70 \%$ & $80 \%$ & $85 \%$ & $78 \%$ \\
\hline & & $\begin{array}{l}\text { b. Tahu } \\
\text { sebagian }\end{array}$ & $30 \%$ & $20 \%$ & $15 \%$ & $32 \%$ \\
\hline & & c. Belum tahu & - & - & - & - \\
\hline & & & - & - & - & - \\
\hline \multirow[t]{4}{*}{4.} & \multirow{4}{*}{$\begin{array}{l}\text { Memahami } \\
\text { komponen- } \\
\text { komponen RPPH }\end{array}$} & a. Tahu & $70 \%$ & $80 \%$ & $85 \%$ & $78 \%$ \\
\hline & & $\begin{array}{l}\text { b. Tahu } \\
\text { sebagian }\end{array}$ & $30 \%$ & $20 \%$ & $15 \%$ & $22 \%$ \\
\hline & & c. Belum tahu & & & - & \\
\hline & & & & - & - & \\
\hline \multirow[t]{4}{*}{5} & \multirow{4}{*}{$\begin{array}{l}\text { Memahami } \\
\text { prinsip-prinsip } \\
\text { RPPH }\end{array}$} & a. Tahu & $64 \%$ & $70 \%$ & $80 \%$ & $71 \%$ \\
\hline & & $\begin{array}{l}\text { b. Sebahagian } \\
\text { tahu }\end{array}$ & $36 \%$ & $30 \%$ & $30 \%$ & $29 \%$ \\
\hline & & & - & - & - & - \\
\hline & & c. Belum tahu & - & - & - & - \\
\hline \multirow[t]{2}{*}{6} & \multirow[t]{2}{*}{ Menyusun RPPH } & $\begin{array}{l}\text { a. Menyusun } \\
\text { benar }\end{array}$ & $69 \%$ & $70 \%$ & $75 \%$ & $71 \%$ \\
\hline & & $\begin{array}{l}\text { b. Menyusun } \\
\text { salah } 15 \text { org }\end{array}$ & $31 \%$ & $30 \%$ & $25 \%$ & $29 \%$ \\
\hline
\end{tabular}


Berdasarkan hasil perhitungan prosentase pada tabel 2 dapat terlihat bahwa kemampuan guru-guru dalam menyusun RPPH sedikit demi sedikit meningkat antara lain yang berkaitan dengan pemahaman terhadap penyusunan RPPH berdasarkan kurikulum 2013 PAUD pada siklus 1 terdapat 50\% dengan kategori "kurang" siklus 2 terdapat 60\% dengan kategori "cukup" siklus 3 terdapat $75 \%$ dengan kategori "baik" dan guru-guru mengetahui benar bahwa penyusunan RPPH tidak maksimal kalau tidak diulang-ulang atau hanya 1 siklus atau satu kali saja. Melalui workshop, guru-guru dapat mengetahui hal-hal terkait penyusunan RPPH. Hal ini dapat meningkat dari siklus ke siklus, karena guru diberikan teori dan juga kesempatan untuk mengkaji buku terkait pemahaman materi tersebut dilanjutkan dengan diskusi.Hal ini memberikan kesempatan kepada guru untuk lebih meningkatkan pengetahuan.

Pada poin memahami kompetensi dasar yang harus dicantumkan pada penyusunan RPPH pada siklus 1 terdapat 60\% atau kategori "cukup", siklus 2 terdapat $65 \%$ atau kategori "cukup", siklus 3 terdapat $70 \%$ atau kategori "baik". Pemahaman terhadap KD tersebut di atas terlihat juga lebih meningkat karena guru diberikan kesempatan membaca dan memahami kemudian bertanya pada hal-hal atau indikator-indikator yang belum dipahami. yang belum dipahami.Setelah dibaca, dilaksanakan diskusi tentang indikator-indikator Kompetensi Dasar (KD). Pada komponen memahami pentingnya penyusunan RPPH pada siklus 1 terdapat terdapat 70\% dengan kategori "baik", siklus 2 terdapat 80\% dengan kategori "baik", siklus 3 terdapat $85 \%$ dengan kategori "baik". Komponen ini juga mengalami peningkatan karena yang lebih baik karena mereka lebih antusias dan lebih aktif dalam mengkaji materi. Guru juga diberikan kegiatan yang sama yaitu membaca dan memahami serta dilanjutkan tanya jawab.

Pada pemahaman terhadap komponen-komponen penyusunan RPPH pada siklus 1 terdapat $70 \%$ dengan kategori "baik, siklus 2 terdapat $80 \%$ dengan kategori "baik", siklus 3 terdapat $85 \%$ dengan kategori "baik". Pada komponen ini sesungguhnya telah lama dipelajari oleh guru-guru bahkan sebelum tindakan guru telah mengkaji karena mereka lebih fokus tentang apa yang akan diajarkan siswanya. Hanya kendala sebelum tindakan, guru agak bingung dalam memetakan ke dalam program semester ke program mingguan dan selanjutnya program harian.Tetapi setelah workshop guru lebih paham tentang komponen-komponen tersebut.

Pada pemahaman prinsip-prinsip penyusunan RPPH pada siklus 1 terdapat $64 \%$ atau kategori "cukup", siklus 2 terdapat 70\% atau kategori "cukup", siklus 3 terdapat $80 \%$ dengan kategori "baik" . Guru-guru lebih memahami prinsip penyusunan RPPH dengan melalui kegiatan membaca dan memahami serta berdiskusi. Pada hasil akhir penyusunan RPPH pada siklus 1 guru yang menyusun benar sebanyak 69\% atau kategori "cukup" siklus 2 terdapat 70\% atau kategori "cukup" siklus 3 terdapat $75 \%$ dengan kategori "baik" Penyusunan RPPH pada siklus 1 diberikan tugas secara berkelompok dengan tujuan yang belum paham dapat belajar kepada temannya yang lebih paham. Dengan kegiatan tersebut dapat mengurangi prosentase jumlah guru yang sebagian paham dan yang belum tahu sebelum tindakan. Pada siklus II diberikan tugas untuk menyusun RPPH secara 
individu dan pada siklus III diberikan tugas untuk menyusun dengan cara berkelompok dari setiap lembaga dengan tujuan dari dari beberapa orang dapat menunjuk 1 orang untuk simulasi.

Secara keseluruhan dengan workshop membuktikan bahwa guru-guru bisa meningkatkan kompetensinya dalam hal penyusunan RPPH, melihat tabel 4.1 dari siklus I ke siklus II, dan dari siklus II ke siklus III ada peningkatan walaupun ada yang belum signifikan. Namun yang jelas, penelitian bisa membuktikan bahwa dugaan awal sebagaimana dituangkan pada latar belakang penelitian terbukti, dan perlu terus memberikan motivasi kepada guru-guru untuk terus meningkatkan kompetensi. Berdasarkan perhitungan akhir rata-rata mengenai kompetensi guru dalam menyusun RPPH, setelah diberi tindakan ternyata optimalisai kompetensi tersebut baru mencapai $71 \%$ tergolong "baik", hal ini disebabkan karena ada beberapa komponen yang belum maksimal dicapai oleh guru antara kemampuan memahami komponen-komponen RPPH termasuk kompetensi dasar yang harus dituangkan pada penyusunan RPPH.

\section{KESIMPULAN}

Berdasarkan hasil analisis data serta pembahasan dapat disimpulkan bahwa pola pembinaan melalui workshop dapat meningkatkan kompetensi guru Taman Kanak-Kanak di Gugus PAUD Rantepao, Kecamatan Rantepao, Kabupaten Toraja Utara dalam menyusun Rencana Pelaksanaan Pembelajaran Harian (RPPH) Upaya meningkatkan kompetensi guru binaan melalui workshop dilaksanakan dengan melalui 3 siklus untuk memberikan materi pembinaan sekaitan dengan penyusunan RPPH. Kompetensi guru binaan dalam menyusun Rencana Pelaksanaan Pembelajaran Harian (RPPH) sebelum diberi perlakuan berupa workshop cenderung berada pada kategori kurang, sedangkan setelah diberi perlakuan berupa workshop cenderung berada pada kategori baik. Dengan demikian kemampuan guru dalam menyusun Rencana Pelaksanaan Pembelajaran Harian (RPPH) cenderung berada pada kategori "Baik". Dengan demikian kompetensi guru dalam menyusun RPPH setelah diberi wokshop lebih baik dari kompetensi dalam menyusun RPPH sebelum diberi kegiatan workshop pada guru-guru binaan di gugus PAUD Kecamatan Rantepao.

\section{DAFTAR PUSTAKA}

Depdiknas. (2003). UU RI No. 20 Tahun 2003 tentang Sistem Pendidikan Nasional. Jakarta: Depdiknas. (2004). Standar Kompetensi Guru Sekolah Dasar. Jakarta: Depdiknas. (2005). UU RI No. 14 Tahun 2005 tentang Guru dan Dosen. Jakarta: Depdiknas. (2005). Standar Nasional Pendidikan. Jakarta: Depdiknas.

(2007). Permendiknas RI No. 41 Tahun $2007 a$ tentang Standar Proses. Jakarta: Depdiknas.

(2007). Permendiknas RI No. 12 Tahun 2007b tentang Standar Pengawas Sekolah/Madrasah. Jakarata: Depdiknas.

(2008). Perangkat Pembelajaran Kurikulum Tingkat Satuan Pembelajaran SMA. Jakarta. 
(2008). Alat Penilaian Kemampuan Guru. Jakarta: Depdiknas.

(2009). Petunjuk Teknis Pembuatan Laporan Penelitian Tindakan Sekolah

Sebagai Karya Tulis Ilmiah Dalam Kegiatan Pengembangan Profesi Pengawas Sekolah. Jakarta.

Kemendiknas. (2010). Penelitian Tindakan Sekolah. Jakarta.

(2018). Supervisi Akademik. Jakarta. 